\title{
Effect of Low-Level Laser Therapy on Proliferation and Collagen Synthesis of Human Fibroblasts in Vitro
}

\author{
Huiling Ma르. Jong-Phil Yang ${ }^{1}$, Rui Ken Tan¹, Hyup-Woo Lee ${ }^{1,2}$, Seung-Kyu Han ${ }^{1}$ \\ ${ }^{1}$ Department of Plastic Surgery, Korea University Guro Hospital, Korea University College of Medicine, Seoul; ${ }^{2}$ Department of Laboratory Medicine, College of \\ Medicine, KangWon National University, Chuncheon, Korea
}

\begin{abstract}
Background: Low-level laser therapy (LLLT) is a nonthermal technology that can be used to modulate cellular activity through light irradiation at specific pulse sequences. In vitro and in vivo studies have been performed previously to determine the effect of LLLT on wound healing. However the results were inconsistent. Final purpose of our project is to determine effect of LLLT on diabetic wound healing and this pilot study was designed to confirm effect of LLLT on activity of healthy human fibroblasts. In particular, we focused on cell proliferation and collagen synthesis, which are main contributing factors in would healing.

Methods: Healthy human fibroblasts obtained from cryopreserved cells $(n=10)$ were irradiated at wavelength of 635 $\mathrm{nm}$ (RED), $830 \mathrm{~nm}$ (IR), and $635 \mathrm{~nm}+830 \mathrm{~nm}$ (FX) with the same fluence of $60 \mathrm{~J} / \mathrm{cm}^{2}$, after seeding into 96-well plates. A group in which no laser exposure was applied was assigned as control. Fibroblast proliferation was examined by EZ-Cytox enhanced cell viability assay and immunohistochemistry (IHC). Collagen synthesis was measured by $\mathrm{IHC}$. $\mathrm{IHC}$ pictures were analyzed to identify the intensity values of collagen type I as quantity results.

Results: Irradiation at FX and IR groups showed a significant increase in fibroblast proliferation and collagen synthesis compared to control and RED groups. There was no significant difference in fibroblast proliferation and collagen synthesis between FX group and IR group.

Conclusion: Healthy human fibroblasts showed better cell proliferation and collagen synthesis when they were irradiated at wavelength of $635 \mathrm{~nm}+830 \mathrm{~nm}$ or $830 \mathrm{~nm}$.
\end{abstract}

Keywords: Fibroblasts, Low-level laser therapy, Wound healing

\section{Introduction}

The prevalence of chronic wounds is increasing dramatically, as the populations of industrialized countries age and become more sedentary. Chronic wounds that respond poorly to conventional treatment, making them very difficult to manage [1]. It is well-known that fibroblasts provide desired growth factors and other substances to accelerate wound healing. However, fibroblasts from chronic wounds such as diabetic ulcers have been commonly demonstrated a lower rate of proliferation when compared with healthy ones [2]. Therefore, it is significant to increase fibroblast activity for accelerating wound healing. The care of chronic wounds has become its own specialty, with providers often using advanced therapies, including growth factors, extracellular matrices (ECMs), engineered skin, and negative pressure wound therapy (NPWT) [3].

Low-level laser therapy (LLLT) is a nonthermal technology that can be used to modulate cellular activity through light irradiation at specific pulse sequences [4]. In vitro and in vivo studies have been performed previously to determine the effect of LLLT on wound healing. However the results were inconsistent. Using a variety of red, blue, yellow, and infrared light wavelength, it has been reported that LLLT can

\section{Original Article}

Received: January 19, 2018

Revised: February 27, 2018

Accepted: February 272018

\section{Corresponding author:}

Seung-Kyu Han, M.D., Ph.D.

Department of Plastic Surgery, Korea University Guro Hospital, Korea University College of Medicine, 148 Gurodong-ro, Guro-gu, Seoul 08308 , Korea

Tel: +82-2-2626-3333

Fax: +82-2-868-6698

E-mall: pshan@kumc.or.kr

This is an Open Access article distributed under the terms of the Creative Commons Attribution Non-Commercial License (http://creativecommons.org/licenses/by-nc/4.0/) which permits unrestricted non-commercial use, distribution, and reproduction in any medium, provided the original work is properly cited.

(c) 2018 Korean Wound Management Society 
accelerate cutaneous wound healing [5]. Clinical benefits of using light irradiation through LLLT on skin wounds are also reported in the literature [6]. Furthermore, it has been reported that LLLT enhances cell proliferation of several cell types including fibroblasts, endothelial cells [7]. However, some studies have suggested that LLLT might have no effect on fibroblast proliferation and activity $[8,9]$. Inhibitory effect on fibroblast proliferation and activity using red light or infrared light were also reported in literature $[10,11]$. Many studies have demonstrated that the effect of light irradiation on human skin fibroblasts is dose and/or wavelength dependent [7-11].

Final purpose of our project is to determine effect of LLLT on diabetic wound healing, which is one of representing chronic wounds. Moreover, this pilot study was designed to confirm effect of LLLT on activity of healthy human fibroblasts. In particular, we focused on cell proliferation and collagen synthesis, which are main contributing factors in would healing.

\section{Methods}

\section{Human dermal fibroblast culture}

Dermal fibroblasts were obtained from cryopreserved cells derived from the dermis of 10 healthy adults who had provided informed consent for their cells to be used for research purposes. Fibroblasts were cultured with Dulbecco's modified Eagle medium/Ham's F-12 nutrient (DMEM/F-12; Gibco, Grand Island, NY, USA) containing 10\% fetal bovine serum (FBS; Gibco) and $25 \mathrm{mg} / \mathrm{mL}$ of gentamycin) in 100-mm tissue culture dishes (Corning Life Sciences, Corning, NY, USA) at $37^{\circ} \mathrm{C}$. All cultures in this study were performed at $37^{\circ} \mathrm{C}$ in a $5 \% \mathrm{CO}_{2}-95 \%$ air atmosphere. Once the culture reached approximately $80 \%$ confluent, fibroblasts were dissociated by trypsinization, diluted 2.7-fold in phosphate-buffered saline without $\mathrm{Mg}^{2+}$ and $\mathrm{Ca}^{2+}$ (PBS; Gibco), and collected by centrifugation at $450 \mathrm{~g}$ for 17 minutes. Cell density was determined by trypan blue dye exclusion test.

To determine the effect of lasers on cell proliferation, $3 \times$ $10^{3}$ cells in $100 \mu \mathrm{L}$ DMEM/F-12 with $5 \%$ FBS were seeded into each well of sterile 96-well culture plates (Fisher Scientific, Pittsburgh, PA, USA). For Immunohistochemistry (IHC) study to evaluate cell proliferation and collagen synthesis, $5 \times 10^{3}$ cells in $200 \mu \mathrm{L}$ DMEM/F-12 with $5 \% \mathrm{FBS}$ were seeded into each well of sterile 8 well cell culture slides (SPL Life Science, Pocheon, Korea). These 96-well plates and 8-well slides were then incubated at $37^{\circ} \mathrm{C}$ overnight to allow human fibroblasts to attach.

\section{Laser irradiation}

Human fibroblasts were irradiated using Light-emitting diode (Smartlux, MEDMIX, Incheon, Korea) in a light room. Three different wavelengths were treated; red light (RED; $635 \pm 6$ $\mathrm{nm})$, infrared light (IR; $830 \pm 5 \mathrm{~nm}$ ), and a dual-wavelength output light (FX; RED+IR). Cells were irradiated with continuous wave at a fluence of $60 \mathrm{~J} / \mathrm{cm}^{2}$ on day 1 and day 3 (48 hours interval between irradiations). The distance from light source to fibroblasts was $15 \mathrm{~cm}$ [12]. Human fibroblasts without any laser exposure were used as controls. Control group plates were taken out of the incubator at the same time and placed in the same ambient environment as their matched treatment plates. On day 5 (48 hours after laser irradiation), cell proliferation and collagen synthesis were measured.

\section{Cell proliferation assay}

On day 5, 96-well plates were subjected to cell proliferation analysis using EZ-Cytox Enhanced Cell Viability Assay Kit (DoGen, DAEILLAB, Seoul, Korea). EZ-Cytox assay measures cell mitochondrial activity based on the conversion of water-soluble tetrazolium salt WST-1 (4-[3-(4-lodophenyl)-2-(4nitrophenyl)-2H-5-tetrazolio]-1, 3-benzene disulfonate) to insoluble formazan. Briefly, cells were incubated with WST-1 reagent for 3 hours. Absorbance was then measured at wavelength of $450 \mathrm{~nm}$ using a 96-well plate reader with reference wavelength of $600 \mathrm{~nm}$.

In addition, 8-well slides were subjected to cell proliferation analysis using $\mathrm{IHC}$ staining. Each group of human fibroblasts was washed twice with ice-cold PBS, fixed with $4 \%$ paraformaldehyde ( $\mathrm{pH} 7.4$ ) in 8-well slides for 30 minutes on ice. Removed the fixative and wash 3 times for 5 minutes each with PBS. Then incubated fibroblasts with $0.5 \%$ Triton X-100 in PBS for 10 minutes at room temperature to permeabilize the membranes, and rinsed three times with PBS. Endogenous peroxidase was then blocked by incubating with 3\% $\mathrm{H}_{2} \mathrm{O}_{2}$ in $\mathrm{PBS}$ at room temperature for 30 minutes. After rinse with PBS 3 times, the 8-well slides were then incubated with primary antibody at $4^{\circ} \mathrm{C}$ overnight. After washing with PBS 3 times, the slides were incubated with corresponding fluorescent dye-conjugated secondary antibody at $37^{\circ} \mathrm{C}$ for 1 hour (protected from light). After fixation, sections were rinsed 3 times with buffer and mounted in $25 \mu \mathrm{L}$ Vector shield with 
DAPI (4'-6-diamidino-2-phenylindole; Vector Laboratories, Burlingame, CA, USA) for staining nuclei.

\section{Collagen synthesis assay}

Collagen type I synthesis assay was performed using IHC staining. The detailed procedure has been described in cell proliferation subsection. These 8-well slides were incubated with primary antibody (anti-collagen type 1; Abcam, Cambridge, MA, USA) and secondary antibody (anti-rabbit-FITC; 1:200, Abcam) for staining collagen type I.

\section{Image acquisition of IHC}

All IHC pictures were taken at the exact center of 8-well slides (200× magnification). Images were analyzed to identify the intensity values of blue color pixel and green color pixel as quantity results, for the reason that nuclei stained by DAPI showed blue color, while collagen type I stained by FITC showed green color in IHC images. Whole slide image analysis was performed using positive pixel count using Adobe Photoshop CS6 (Adobe Systems, San José, CA, USA).

\section{Statistical analysis}

All experiments were performed in triplicates and average value was used as each data. Results are expressed as means \pm standard deviations. Statistical comparisons were performed with Wilcoxon signed ranks test and paired t-test. Statistical significance was considered at $P<0.05$. Data were analyzed using Statistical Product and Service Solutions version 20 (SPSS; Systat Software, IBM, Armonk, NY, USA).

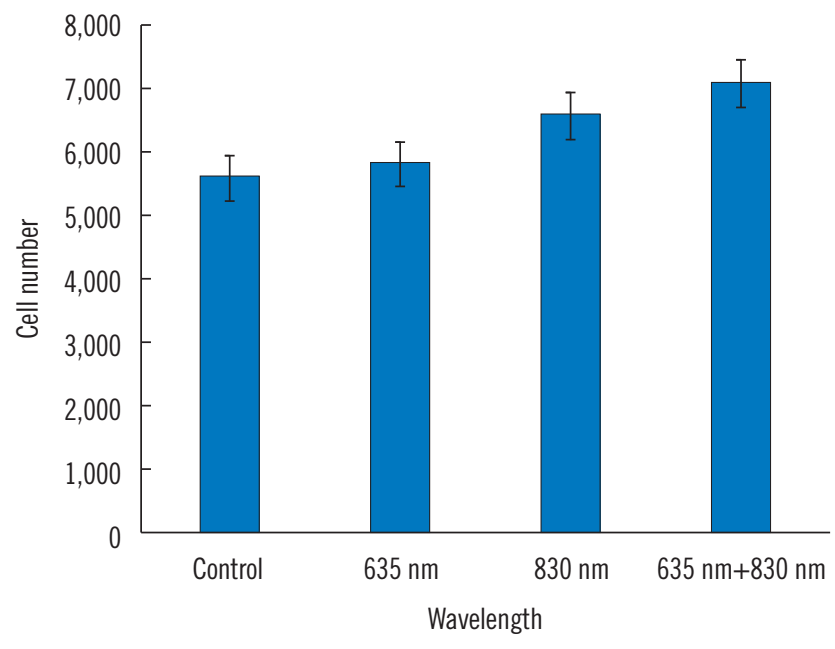

Fig. 1. Result of cell number using EZ-Cytox kit.

\section{Results}

\section{Cell proliferation}

In cell proliferation analysis using EZ-Cytox Kit, FX group (635 $\mathrm{nm}+830 \mathrm{~nm}$ ) demonstrated highest cell number, followed by $\mathrm{IR}$ and RED groups. Cell proliferation in the FX and IR groups showed statistically significant differences compared with RED and control group. However, there was no statistically significant difference between FX and IR groups (Fig. 1 and Table 1). Results of IHC study are shown in Figs. 2, 3, and Table 2 which were consistent with results of EZ-Cytox analysis.

\section{Collagen synthesis assays}

Collagen synthesis was increased in all irradiated groups compared to that in the control group. However, statistically

Table 1. Statistical significances in cell proliferation analysis using EZ-Cytox

\begin{tabular}{lcccc}
\hline & Control & $635 \mathrm{~nm}$ & $830 \mathrm{~nm}$ & $635 \mathrm{~nm}+830 \mathrm{~nm}$ \\
\hline Control & - & 0.391 & $* *$ & $*$ \\
$635 \mathrm{~nm}$ & 0.391 & - & $* *$ & $* *$ \\
$830 \mathrm{~nm}$ & $* *$ & $* *$ & - & 0.113 \\
$635 \mathrm{~nm}+830 \mathrm{~nm}$ & $*$ & $* *$ & 0.113 & -
\end{tabular}

${ }^{*} \mathrm{P}<0.001,{ }^{* * \mathrm{P}}<0.01$.
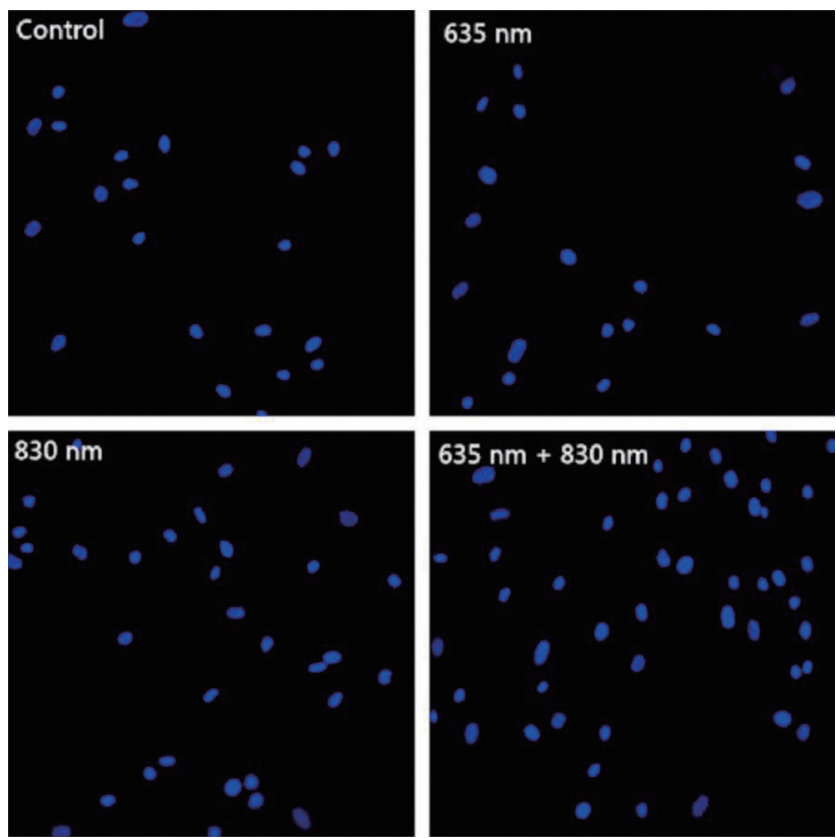

Fig. 2. Representative samples of cell number study using immunohistochemistry. 


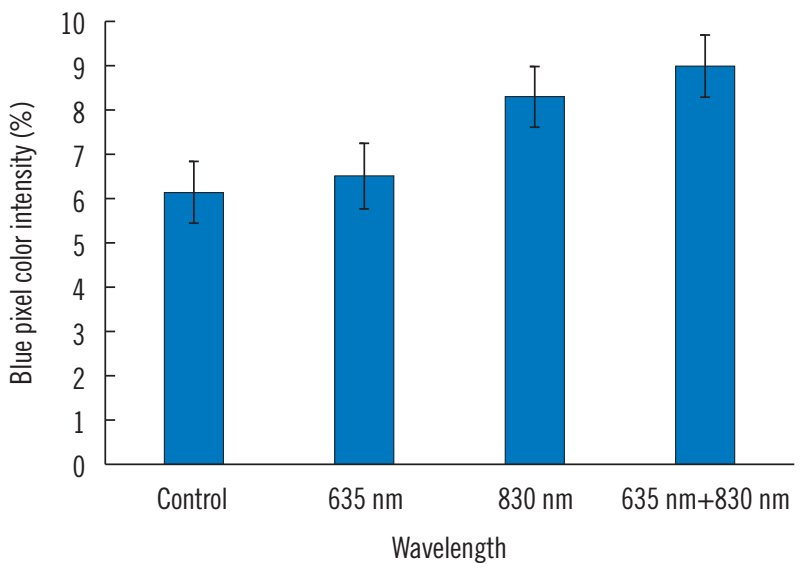

Fig. 3. Result of cell number using immunohistochemistry.

Table 2. Statistical significances in cell proliferation analysis using IHC staining

\begin{tabular}{lcccc}
\hline & Control & $635 \mathrm{~nm}$ & $830 \mathrm{~nm}$ & $635 \mathrm{~nm}+830 \mathrm{~nm}$ \\
\hline Control & - & 0.264 & $* * *$ & $*$ \\
$635 \mathrm{~nm}$ & 0.264 & - & $* * *$ & $* *$ \\
$830 \mathrm{~nm}$ & $* * *$ & $* * *$ & - & 0.348 \\
$635 \mathrm{~nm}+830 \mathrm{~nm}$ & $*$ & $* *$ & 0.348 & - \\
\hline
\end{tabular}

${ }^{*} \mathrm{P}<0.001,{ }^{* * \mathrm{P}}<0.01,{ }^{* * * \mathrm{P}}<0.05$.

Table 3. Statistical significances in collagen synthesis analysis using IHC staining

\begin{tabular}{lcccc}
\hline & Control & $635 \mathrm{~nm}$ & $830 \mathrm{~nm}$ & $635 \mathrm{~nm}+830 \mathrm{~nm}$ \\
\hline Control & - & 0.221 & $*$ & $*$ \\
$635 \mathrm{~nm}$ & 0.221 & - & $* *$ & $*$ \\
$830 \mathrm{~nm}$ & $*$ & $* *$ & - & 0.123 \\
$635 \mathrm{~nm}+830 \mathrm{~nm}$ & $*$ & $*$ & 0.123 & - \\
\hline
\end{tabular}

${ }^{*} \mathrm{P}<0.001,{ }^{* * \mathrm{P}}<0.01$.

significant differences were detected in IR group and FX group (Figs. 4, 5, and Table 3).

\section{Discussion}

According to previous research, LLLT has effect on energy and absorption levels of cells relevant to their respiratory chains [13]. This indicates that LLLT can stimulate components of the so-called antenna pigments of the respiratory chain of cells by using electromagnetic energy, therefore sensitizing cells by increasing mitochondrial ATP production [14]. Electromagnetic radiation in the form of light can vitalize macromolecules depending on wavelength. It can initiate confor-
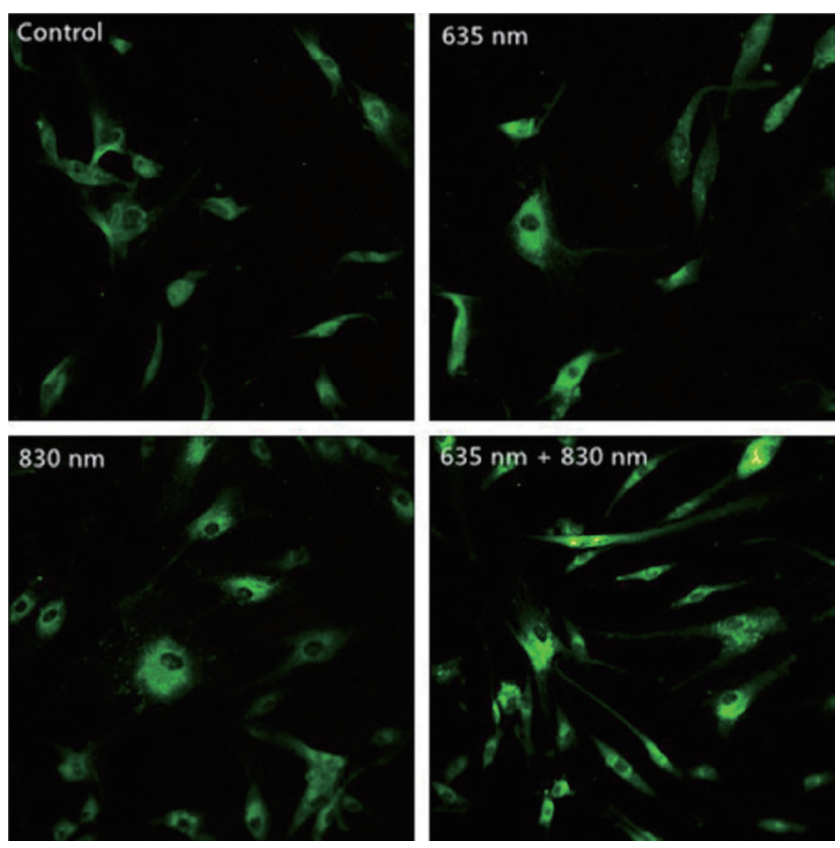

Fig. 4. Representative samples of collagen synthesis study using immunohistochemistry.

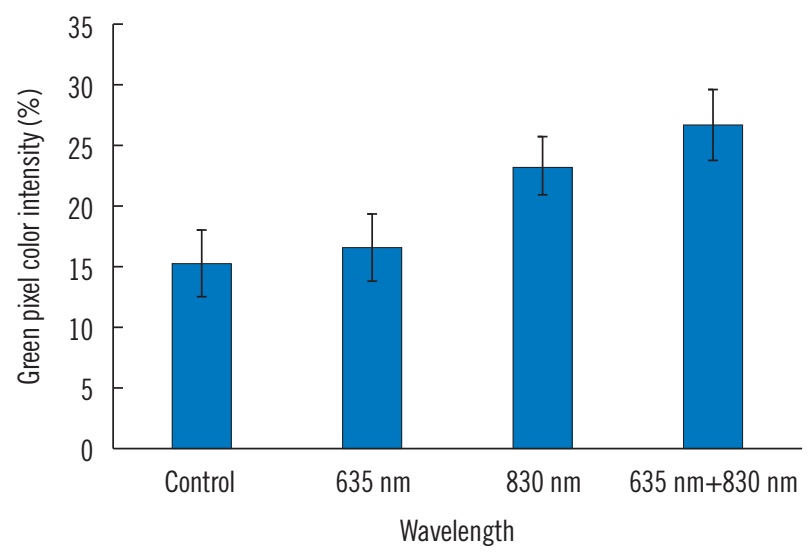

Fig. 5. Result of collagen synthesis using immunohistochemistry.

mation changes in proteins and transfer energy to electrons [15]. Absorption of a specific wavelength of light can affect functioning photoreceptor (photoacceptor) molecule in the metabolic pathway involving redox chains [16]. It is known that an action spectrum follows the absorption spectrum of the photoacceptor molecule within certain limits $[13,16]$. For these reason, wavelength can play a fatal role in LLLT. As mentioned earlier, the preferred wavelength to stimulate fibroblast proliferation at visible red light or invisible infrared light remain controversial.

Another optimal parameter for LLLT is fluence. Exposure to lower-fluence laser light (from 0.09 to $20 \mathrm{~J} / \mathrm{cm}^{2}$ ) [17] and 
medium-fluence laser light $\left(20-80 \mathrm{~J} / \mathrm{cm}^{2}\right)[11,13]$ tends to accelerate cell growth and wound-healing, whereas higherfluence light (more than $80 \mathrm{~J} / \mathrm{cm}^{2}$ ) [18] negates the beneficial effect of laser exposure. However, no significant difference or inhibited effect in fibroblast proliferation has also been found using lower-fluence laser light in several studies $[8,10]$. Therefore, lower-fluence laser light remaining controversial also would not be an option for our study. A similar conclusion has also been found by Luciana Almeida-Lopes [19]. As a result, the better choice of fluence for our study was to use one of medium-fluence laser light $[4,12]$. The fluence at 60 $\mathrm{J} / \mathrm{cm}^{2}$ was used in our study. However, a dose-dependent study is needed in the future to definitely determine its effect on cell proliferation and collagen synthesis of fibroblasts.

Our findings indicated that LLLT at wavelength of $830 \mathrm{~nm}$ or $635 \mathrm{~nm}+830 \mathrm{~nm}$ with fluence of $60 \mathrm{~J} / \mathrm{cm}^{2}$ could modulate fibroblast proliferation and collagen synthesis, with cells irradiated at $635 \mathrm{~nm}+830 \mathrm{~nm}$ possibly giving better results. It is difficult to compare our results with observations of other studies in the literature, because most studies have reported only one or two different single wavelength and treatment design varies depending on individual studies $[10,11]$. However, some studies have been performed in a similar manner to our study [12,20,21]. Bogdan Crisan has compared near-infrared laser light at wavelength of $830 \mathrm{~nm}, 980 \mathrm{~nm}$, and $2,940 \mathrm{~nm}$. Whereas, these three wavelength are actually is in the same spectrum. Among these three wavelength, irradiation at $830 \mathrm{~nm}$ showed the most notable bio-stimulation effect on human skin fibroblasts [21]. For comparison between two kinds of spectrum (visible red light and infrared light), some studies have demonstrated that infrared low level lasers are preferred over visible red light lasers in stimulating cell proliferation or collagen synthesis $[12,19]$. These results are similar to results of the present study. It has been reported that $780 \mathrm{~nm}$ laser light can up-regulate the production of basic fibroblastic growth factor (bFGF) more than $660 \mathrm{~nm}$ visible red laser [12]. Diabetic fibroblasts irradiated at $830 \mathrm{~nm}$ have shown more bFGF release compared to those irradiated at $632.8 \mathrm{~nm}[20]$.

Previous studies have demonstrated action mechanisms of visible to near-infrared radiation on cells. It has been suggested that we should pay an attention to energy values relevant to the respiratory chain of cells. The effect of electromagnetic wavelength on cellular energy transfer has become evident [16]. Tiina Karu reported that absorbing molecule can transfer energy to another molecule and that the activated molecule can then cause chemical reactions in surrounding tissue as the basis for LLLT effect [13]. Moreover, cytochromes c oxidase (red and near-infrared light region) is one of the primary photoacceptors reported in the literature. Cofactors for cytochromes c oxidase and cytochromes b, c1, and $\mathrm{c}$ are porphyrins while cofactors for complex I (an enzyme of the respiratory chains) are flavins [22]. These changes in mitochondrial respiratory chain can mediate the activation or suppression of signal molecules in the cytoplasm, causing subsequent changes of downstream cascades and leading to the synthesis of DNA, RNA, proteins, and enzymes in the nucleus, cytoplasm, or plasma membrane. Finally, these changes will result in photobiological effects of cells such as cell proliferation and differentiation [23, 24]. Therefore, we speculated that dual-wavelength (635 $\mathrm{nm}+830 \mathrm{~nm}$ ) could have better effects on fibroblast proliferation and collagen synthesis through both red region and nearinfrared region action spectrum by increasing the range of photoacceptor molecule. However, according the present study, we can't demonstrate that there are significant difference in cellular response of human fibroblasts between 830 $\mathrm{nm}$ and $635 \mathrm{~nm}+830 \mathrm{~nm}$, may be due to the less amount of case. A further study is needed in the future to confirm it. The results of the present study may suggest that dual-wavelength light $(635 \mathrm{~nm}+830 \mathrm{~nm})$ could be an optimal choice for LLLT to improve the wound-healing. Our results might help clinicians in the choice of wavelength appropriate for LLLT.

As a conclusion, our study demonstrated that dual-wavelength light ( $635 \mathrm{~nm}+830 \mathrm{~nm}$ ) or infrared light $(830 \mathrm{~nm})$ has stimulating effect on proliferation and collagen synthesis of human fibroblasts in vitro. However, visible red light (635 nm) does not.

\section{Conflict of interest}

No potential conflict of interest relevant to this article was reported.

\section{Acknowledgment}

This article was presented as a oral presentation at the Internarional 75th Congress of the Korean Society of Plastic and Reconstructive Surgeons on Nov 10-12, 2017. 


\section{References}

1. You HJ, Namgoong S, Han SK, et al. Wound-healing potential of human umbilical cord blood-derived mesenchymal stromal cells in vitro--a pilot study. Cytotherapy 2015;17(11): 1506-13.

2. Hehenberger K, Kratz G, Hansson A, et al. Fibroblasts derived from human chronic diabetic wounds have a decreased proliferation rate, which is recovered by the addition of heparin. J Dermatol Sci 1998;16(2):144-51.

3. Shankaran V, Brooks M, Mostow E. Advanced therapies for chronic wounds: NPWT, engineered skin, growth factors, extracellular matrices. Dermatol Ther 2013;26(3):215-21.

4. Oh IY, Kim BJ, Kim MN, et al. Efficacy of light-emitting diode photomodulation in reducing erythema after fractional carbon dioxide laser resurfacing: a pilot study. Dermatol Surg 2013;39(8):1171-6.

5. Yeh NG, Wu CH, Cheng TC. Light-emitting diodes-Their potential in biomedical applications. Renew Sust Energ Rev 2010;14(8):2161-66.

6. Chaves ME, Araujo AR, Piancastelli AC, et al. Effects of lowpower light therapy on wound healing: LASER $\times$ LED. An Bras Dermatol 2014;89(4):616-23.

7. Moore P, Ridgway TD, Higbee RG, et al. Effect of wavelength on low-intensity laser irradiation-stimulated cell proliferation in vitro. Lasers Surg Med 2005;36(1):8-12.

8. Abrahamse H, Houreld N, Muller S, et al. Fluence and wavelength of low intensity laser irradiation affect activity and proliferation of human adipose derived stem cells: peer reviewed original article. Medical Technology SA 2010;24(2): 15-20.

9. Pereira AN, Eduardo Cde P, Matson E, et al. Effect of lowpower laser irradiation on cell growth and procollagen synthesis of cultured fibroblasts. Lasers Surg Med 2002;31(4): 263-7.

10. Hawkins D, Abrahamse H. Biological effects of helium-neon laser irradiation on normal and wounded human skin fibroblasts. Photomed Laser Surg 2005;23(3):251-9.

11. Tada K, Ikeda K, Tomita K. Effect of polarized light emitting diode irradiation on wound healing. J Trauma 2009;67(5): 1073-9.

12. Yoo KH, Yeo IK, Hyun MY, et al. Efficacy of combination light-emitting diode (635 and $830 \mathrm{~nm}$ ) therapy in treating lo- cal injection-site reactions after filler. Clin Exp Dermatol 2015;40(3):333-5.

13. Karu T. Photobiology of low-power laser effects. Health Phys 1989;56(5):691-704.

14. Karu T. Photobiological fundamentals of low-power laser therapy. IEEE J Quantum Elect 1987;23(10):1703-1717.

15. Wilden L, Karthein R. Import of radiation phenomena of electrons and therapeutic low-level laser in regard to the mitochondrial energy transfer. J Clin Laser Med Surg 1998; 16(3):159-65

16. Karu T. Primary and Secondary Mechanisms of Action of Visible to near-IR Radiation on Cells. J Photochem Photobiol 1999 March [Epub]. https://doi.org/10.1016/S1011-1344 (98)00219-X

17. Hawkins D, Abrahamse $\mathrm{H}$. Effect of multiple exposures of low-level laser therapy on the cellular responses of wounded human skin fibroblasts. Photomed Laser Surg 2006;24(6): 705-14.

18. Lev-Tov H, Mamalis A, Brody N, et al. Inhibition of fibroblast proliferation in vitro using red light-emitting diodes. Dermatol Surg 2013;39(8):1167-70.

19. Almeida-Lopes L, Rigau J, Zangaro RA, et al. Comparison of the low level laser therapy effects on cultured human gingival fibroblasts proliferation using different irradiance and same fluence. Lasers Surg Med 2001;29(2):179-84.

20. Crisan B, Soritau O, Baciut M, et al. Influence of three laser wavelengths on human fibroblasts cell culture. Lasers Med Sci 2013;28(2):457-63.

21. Houreld N, Abrahamse H. Low-intensity laser irradiation stimulates wound healing in diabetic wounded fibroblast cells (WS1). Diabetes Technol Ther 2010;12(12):971-8.

22. Giese AC. Photosensitization of Organisms, with Special Reference to Natural Photosensitizers. In: Hillenkamp F, Pratesi R, Sacchi CA, eds. Lasers in Biology and Medicine. Boston, MA: Springer US, 1980:299-314.

23. Gao X, Xing D. Molecular mechanisms of cell proliferation induced by low power laser irradiation. J Biomed Sci 2009; 16(1):4.

24. Saperia D, Glassberg E, Lyons RF, et al. Demonstration of elevated type I and type III procollagen mRNA levels in cutaneous wounds treated with helium-neon laser: proposed mechanism for enhanced wound healing. Biochem Biophys Res Commun 1986;138(3):1123-28. 